\title{
Treatment with TNF- $\alpha$ or bacterial lipopolysaccharide attenuates endocardial endothelial cell-mediated stimulation of cardiac fibroblasts
}

\author{
Leena Kuruvilla ${ }^{1}$ and Cheranellore Chandrasekharan Kartha*1,2
}

\author{
Address: ${ }^{1}$ Division of Cellular \& Molecular Cardiology, Sree Chitra Tirunal Institute for Medical Sciences and Technology, Thiruvananthapuram \\ 695011, India and 2Professor of Eminence, Disease Biology and Molecular Medicine, Rajiv Gandhi Center for Biotechnology, \\ Thiruvananthapuram 695014, India \\ Email: Leena Kuruvilla - leenamary24@yahoo.com; Cheranellore Chandrasekharan Kartha* - cckartha@rgcb.res.in \\ * Corresponding author
}

Published: 17 February 2009

Journal of Biomedical Science 2009, 16:21 doi:10.1186/1423-0127-16-21

This article is available from: http://www.jbiomedsci.com/content//6/I/2I

(C) 2009 Kuruvilla and Kartha; licensee BioMed Central Ltd.

This is an Open Access article distributed under the terms of the Creative Commons Attribution License (http://creativecommons.org/licenses/by/2.0), which permits unrestricted use, distribution, and reproduction in any medium, provided the original work is properly cited.
Received: 16 August 2008

Accepted: 17 February 2009

\begin{abstract}
Background: The endocardial endothelium that lines the inner cavity of the heart is distinct from the microvascular endothelial cells and modulates cardiac muscle performance in a manner similar to the vascular endothelial modulation of vascular structure and vasomotor tone. Although the modulatory effects of endocardial endothelium (EE) on cardiomyocytes are firmly established, the regulatory effects of endocardial endothelium on the cardiac interstitium and its cellular components remain ill defined.
\end{abstract}

Methods and Results: We investigated whether the stimulatory effect of EE on cardiac fibroblasts would be altered when EECs are activated by the cytokine tumor necrosis factor- $\alpha$ (TNF- $\alpha$ ) or the endotoxin bacterial lipopolysaccharide (LPS). Both TNF- $\alpha$ and LPS were found to independently attenuate the stimulatory effect of EE on cardiac fibroblasts. These agents lowered the synthesis or release of ET-I and increased the secretion of TGF- $\beta$ and NO.

Conclusion: The findings of this study using endocardial endothelial cells (EECs) and neonatal cardiac fibroblasts demonstrate that pro-inflammatory cytokines cause altered secretion of paracrine factors by EECs and inhibit proliferation and lower collagen synthesis in fibroblasts. These changes may influence fibroblast response and extra cellular matrix remodeling in pathological conditions of the heart.

\section{Background}

The endocardial endothelium (EE) that lines the inner cavity of the heart is distinct from the microvascular endothelial cells in terms of embryological origin, cytoskeletal organization, receptor - mediated functions, electrophysiological properties, release of prostanoids and growth characteristics in culture [1]. The EE is strategically situated between the circulating blood and the car- diac muscle and it modulates cardiac muscle performance exactly as the vascular endothelium modulates vascular structure and vasomotor tone. Brutsaert et al [2] have demonstrated that EE is an important modulator of subjacent cardiac muscle performance. Dysfunction of this interface could be a critical factor in various pathological conditions of the heart. Evidence of physiologically significant paracrine interactions between the endocardial cell 
populations and muscle cells of the heart accrued from studies on factors of endothelial origin such as endothelins, angiotensin II, nitric oxide (NO), natriuretic peptides, bradykinin prostaglandins, adenylpurines, myofilament desensitizing element and enzymes such as angiotensin converting enzyme and kininase. Importantly, an imbalance in the turnover of these factors in cardiovascular diseases may potentially promote alterations in the extra cellular matrix (ECM) and disturb cardiomyocyte function. In fact, heart function is reported to be significantly affected by increased cytokine production in a setting of endotoxic shock, transplant rejection and ischemia/reperfusion [3]. Endothelium derived factors such as TNF- $\alpha$, IL-1 $\beta$, IL- 6 and TGF- $\beta$ may exert autocrine and paracrine effects on fibroblast growth and collagen turnover as well.

Whereas the modulatory influence of EE on cardiomyocytes is well established, the effects of EE on the cardiac interstitium and its cellular components particularly the fibroblasts, which maintain the extracellular matrix homeostasis are far less defined [4]. In this regard, we had recently reported a significant increase in cardiac fibroblast proliferation and collagen synthesis when the cells are grown in EEC conditioned media [5]. In the present study, we investigated whether the stimulatory effect of EE on cardiac fibroblasts would be altered in conditions where TNF- $\alpha$ or the endotoxin bacterial LPS activates EECs. Our results suggest that TNF- $\alpha$ or LPS - activated EE cells attenuate proliferation and collagen synthesis in cardiac fibroblasts.

\section{Materials and methods}

Tissue culture media and all supplements were procured from Sigma-Aldrich, St. Louis, USA. [ $\left.{ }^{3} \mathrm{H}\right]$-Thymidine and [ $\left.{ }^{3} \mathrm{H}\right]$-Proline was obtained from Board of Radioactivity and Isotope Technology (BRIT), Mumbai, India. DiIAcetylated LDL was purchased from Molecular Probes, Netherlands.

\section{Preparation of cultures of endocardial endothelial cells}

Endocardial endothelial cells were isolated from freshly collected pig hearts by the method previously described by Smith et al [6]. Briefly, the ventricles were filled with $0.1 \%$ collagenase (Type IA) in medium E199 and incubated for 45 minutes. The released cells were resuspended in complete medium (medium E199 supplemented with $20 \%$ fetal bovine serum (FBS), 1\% endothelial cell growth factor, $100 \mathrm{U} / \mathrm{ml}$ benzyl penicillin and $100 \mu \mathrm{g} / \mathrm{ml}$ streptomycin) and seeded in gelatin - coated culture dishes. Confluent cultures were sub - cultured using 0.025\% trypsin - $0.02 \%$ EDTA. The cells were identified as endothelial cells by their cobblestone appearance, positive staining for factor VIII antigen and incorporation of DiI-acetylated low-density lipoproteins.

\section{Preparation of cultures of cardiac fibroblasts}

Cardiac fibroblasts were isolated from 3- to 4-day-old Wistar rat pups. The heart tissue was minced and digested with $0.03 \%$ collagenase and $0.03 \%$ trypsin. The supernatants were centrifuged and cell pellet was resuspended in medium M199 with 10\% FBS. Cardiac fibroblasts attached within 90 minutes. The cells were grown to confluence and passaged with $0.025 \%$ trypsin-0.02\% EDTA mixture. The cells were identified as fibroblasts by their spindle morphology, positive staining for vimentin and negative staining for factor VIII antigen.

All experiments had the approval of the Institutional Animal Ethics Committee.

\section{Preparation of conditioned medium}

The experiments were performed on EECs from the $3^{\text {rd }}$ $4^{\text {th }}$ passages. Cells were seeded at a density of $2 \times 10^{5}$ cells/ $\mathrm{ml}$ in $35 \mathrm{~mm}$ culture dishes. At confluence, the cells were made quiescent by reducing the serum content of the medium to $0.4 \%$ for 24 hours. On the day of the experiment, the cells were washed with phosphate - buffered saline and treated with either $10 \mathrm{ng} / \mathrm{ml}$ TNF- $\alpha$ or $1 \mu \mathrm{g} / \mathrm{ml}$ bacterial LPS. Cells incubated in $0.4 \%$ FBS containing medium served as control. At the end of the incubation period of 24 hours, the medium was collected, centrifuged to remove cellular debris and stored at $-80^{\circ} \mathrm{C}$ until use. Dulbecco's modified Eagle's medium (DMEM) was used for generating conditioned medium for the collagen synthesis experiments.

\section{Proliferation assay}

DNA synthesis in cardiac fibroblasts was measured in terms of $\left[{ }^{3} \mathrm{H}\right]$-Thymidine incorporation into DNA $(\mathrm{n}=$ $15)$ as described earlier [7]. Cells were seeded at a density of $1 \times 10^{5}$ cells $/ \mathrm{ml}$ and incubated for 24 hours. Cells from passage 2 were made quiescent by incubating them in medium containing $0.4 \%$ FBS for 24 hours. Following incubation of the cells with $\left[{ }^{3} \mathrm{H}\right]$-Thymidine at a final concentration of $1 \mu \mathrm{Ci} / \mathrm{ml}$ for 24 hours, acid - insoluble radioactivity was determined by using liquid scintillation spectrometry.

\section{Collagen synthesis assay}

Incorporation of $\left[{ }^{3} \mathrm{H}\right]$-Proline by cardiac fibroblasts was taken as a measure of collagen synthesis $(n=9)$. Cardiac fibroblasts at confluence were incubated in DMEM supplemented with $0.4 \%$ FBS, 24 hours prior to treatment. Subsequently, cells were incubated for 24 hours in either $0.4 \%$ FBS or EEC - conditioned medium, containing 2 $\mu \mathrm{Ci} / \mathrm{ml}\left[{ }^{3} \mathrm{H}\right]$-Proline and $50 \mu \mathrm{g} / \mathrm{ml}$ ascorbic acid in DMEM. The supernatant was collected and cells were lysed using 1\% Triton-X 100 containing 5 mM N-ethylmaleimide. The cell lysate and medium were pooled and the mixture divided into two aliquots. Proteins in one 
aliquot were precipitated with $10 \%$ ice-cold TCA. The second aliquot was digested with $30 \mu \mathrm{g} / \mathrm{ml}$ collagenase Type VII in Tris- $\mathrm{CaCl}_{2}$ buffer $(\mathrm{pH}-7.4)$ for 5 hours at $37^{\circ} \mathrm{C}$. At the end of collagenase digestion, the proteins were precipitated with $10 \%$ ice-cold TCA. The TCA-precipitated material in the two aliquots was filtered separately onto Whatman no.3 filter paper. Radioactivity was determined using a scintillation counter. Collagen synthesis was calculated using the equation:

Collagen $(\%$ of total protein $)=\frac{\text { Collagenase released } \mathrm{cpm} \times 100}{(\text { Non-collagen } \mathrm{cpm} \times \mathrm{f})+\text { collagenase released } \mathrm{cpm}}$

A correction factor of $\mathrm{f}=5.4$ for non-collagen protein was used to adjust for the relative abundance of proline and hydroxyproline in collagen containing proteins [8].

\section{Measurement of EEC - derived factors in the conditioned medium}

The conditioned medium was assayed $(n=6)$ for the levels of EEC - derived factors, ET-1 (Cayman Chemical, MI, USA), Ang II (SPI BIO, France) and TGF- $\beta 1$ (Biosource International, Belgium) by ELISA using commercially available kits.

\section{Statistics}

Sample means were compared using Student's t-test. ANOVA was employed for group comparisons where there were more than two groups. The values are expressed as mean $\pm S D$. $p<0.05$ was considered statistically significant.

\section{Results}

Effect of TNF- $\alpha$ and LPS on EEC-induced proliferation of cardiac fibroblasts

On incubation with EE - conditioned medium, $\left[{ }^{3} \mathrm{H}\right]$-Thymidine incorporation into cardiac fibroblast DNA increased by $22 \%$. The stimulatory effect was however attenuated when cardiac fibroblasts were incubated in medium conditioned by TNF- $\alpha$ or LPS treated EECs. $\left[{ }^{3} \mathrm{H}\right]-$ Thymidine counts per minute (cpm) with medium conditioned by untreated EECs was $49678 \pm 418.7$. [ $\left.{ }^{3} \mathrm{H}\right]$-Thymidine counts per minute ( $\mathrm{cpm}$ ) with medium conditioned by EECs treated with TNF- $\alpha$ or LPS were $45271.7 \pm 1008.7$ cpm and $45163.6 \pm 802.5 \mathrm{cpm}$ respectively. The basal $\left[{ }^{3} \mathrm{H}\right]$-Thymidine counts per minute $(\mathrm{cpm})$ with $0.4 \%$ M199 was $40676 \pm 985 \mathrm{cpm}$. Thus, TNF- $\alpha$ treated EECs attenuated $\left[{ }^{3} \mathrm{H}\right]$-Thymidine incorporation into DNA of cardiac fibroblasts by $11.3 \%(\mathrm{n}=15 ; \mathrm{p}<0.01)$ and LPS treated EECs attenuated $\left[{ }^{3} \mathrm{H}\right]$-Thymidine incorporation into DNA of cardiac fibroblasts by $11 \%(\mathrm{n}=15 ; \mathrm{p}<0.01)$ (Figure 1).

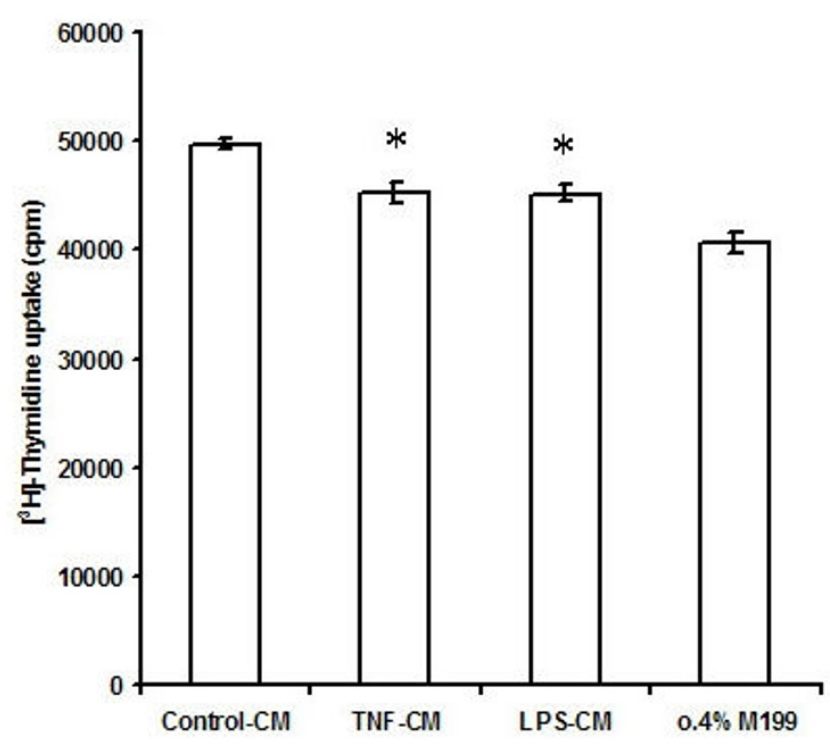

Figure I

( $\left.{ }^{3} \mathrm{H}\right)$-Thymidine uptake by cardiac fibroblasts incubated with conditioned medium from EECs treated with TNF- $\alpha$ and LPS. The values are mean \pm SD $(n=15$; Control-CM vs TNF-CM \& Control-CM vs LPS-CM, ${ }^{*}$ < $<$ 0.01 . Control-CM vs. $0.4 \%$ MI 99, * $\mathrm{p}<0.01$ ). Control-CM = Fibroblasts grown in conditioned medium from untreated endocardial endothelial cells, TNF-CM = Fibroblasts grown in conditioned medium from endocardial endothelial cells treated with TNF- $\alpha$, LPS-CM = Fibroblasts grown in conditioned medium from endocardial endothelial cells treated with LPS, $0.4 \%$ MI 99 = Fibroblasts grown in MI 99 containing $0.4 \%$ FBS. ' $n$ ' is the number of times each experiment was done.

\section{Effect of TNF- $\alpha$ and LPS on EEC-induced collagen synthesis by cardiac fibroblasts}

The effect of medium conditioned by TNF- $\alpha$ or LPS treated EECs, on collagen synthesis by cardiac fibroblasts is shown in Figure 2. The basal rate of collagen synthesis by cardiac fibroblasts in $0.4 \% \mathrm{M} 199$ was $6.51 \pm 1.0 \%$ of the total protien and by fibroblasts grown in medium conditioned by untreated EECs was $10.6 \pm 0.9 \%$ of the total protien. Collagen synthesis by cardiac fibroblasts was reduced to $4.85 \pm 0.9 \%$ and $5.12 \pm 1 \%$ of the total protein respectively when the cells were grown in medium conditioned by TNF- $\alpha$ or LPS treated EECs $(\mathrm{n}=6$; Control-CM vs TNF-CM and LPS-CM, $\mathrm{p}<0.05$ ). Whereas a 6 $\%$ increase in collagen synthesis was seen in fibroblasts grown in medium conditioned by untreated EECs, rate of collagen synthesis in cardiac fibroblasts incubated with conditioned medium from EECs treated with TNF- $\alpha$ or LPS was seen to decrease by $25 \%$ and $21 \%$ respectively, compared to the control (Figure 2). 


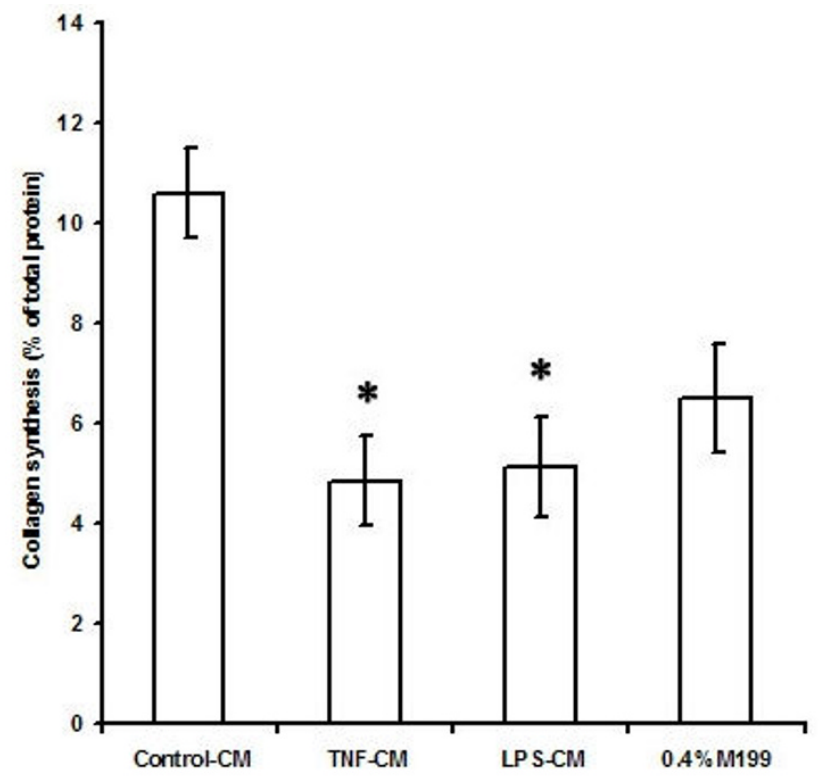

Figure 2

Collagen synthesis by cardiac fibroblasts in response to incubation with conditioned medium from endocardial endothelial cells treated with TNF- $\alpha$ and LPS for 24 hours. The values are mean $\pm S D(n=6$; Control-CM vs TNF-CM and LPS-CM, *p $<0.05$. Control-CM vs $0.4 \%$ MI99*p < 0.05). Control-CM = Fibroblasts grown in conditioned medium from untreated endocardial endothelial cells, TNF-CM = Fibroblasts grown in conditioned medium from endocardial endothelial cells treated with TNF- $\alpha$, LPS-CM = Fibroblasts grown in conditioned medium from endocardial endothelial cells treated with LPS, $0.4 \%$ MI $99=$ Fibroblasts grown in MI 99 containing $0.4 \%$ FBS. ' $n$ ' is the number of times each experiment was done.

\section{Assay of endocardial endothelial cell released factors in the culture supernatants}

Levels of endothelium-derived factors ET-1, AII, and TGF$\beta 1$, were determined by ELISA according to the manufacturer's protocols. NO released into the medium was measured as nitrite by Griess reaction.

Treatment of EECs with TNF- $\alpha$ and LPS caused increased release of nitrite from the cells into the culture supernatant. The amount of nitrite released into the medium conditioned by untreated EECs was $1.81 \pm 0.17 \mu \mathrm{M}$. TNF- $\alpha$ or LPS treatment of EECs increased nitrite levels in the culture supernatant to $2.86 \pm 0.29 \mu \mathrm{M}$ and $4.48 \pm 0.44 \mu \mathrm{M}$ respectively $(\mathrm{n}=6$; $\mathrm{p}<0.05)$. Thus, stimulation of EECs with TNF- $\alpha$ or LPS increased nitrite release from EECs by $58 \%$ and $147 \%$ respectively (Figure 3 ).

ET-1 levels and TGF- $\beta$ levels in the culture supernatant of EECs treated with TNF- $\alpha$ were $5.56 \pm 0.02 \mathrm{ng} / \mathrm{ml}$ and 7.21

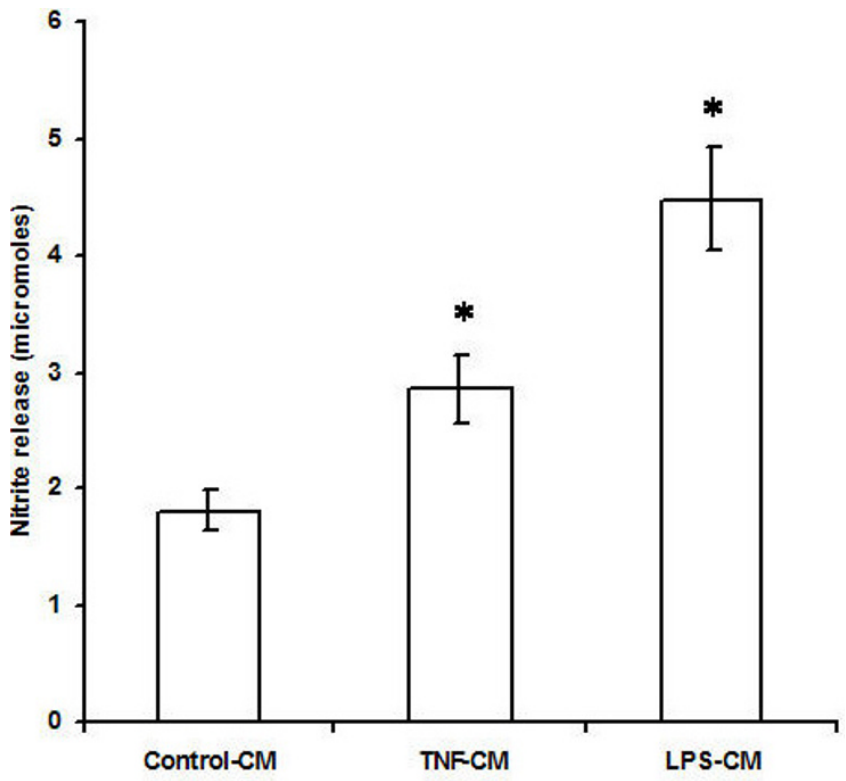

Figure 3

Nitrite release by endocardial endothelial cells in response to proinflammatory agents TNF- $\alpha$ and LPS. The values are mean \pm SD $\left(n=6 ; *^{*}<0.05\right)$. Control-CM = Conditioned medium from untreated endocardial endothelial cells, TNF-CM = Conditioned medium from endocardial endothelial cells treated with TNF- $\alpha$, LPS-CM = Conditioned medium from endocardial endothelial cells treated with LPS. ' $n$ ' is the number of times each experiment was done.

$\pm 0.1 \mathrm{ng} / \mathrm{ml}$ respectively compared to ET -1 and TGF- $\beta$ levels of $6.6 \pm 0.01 \mathrm{ng} / \mathrm{ml}$ and $6.56 \pm 0.05 \mathrm{ng} / \mathrm{ml}$ respectively in the culture supernatant of untreated EECs $(n=6 ; p<$ 0.01 ). Thus, TNF- $\alpha$ depressed the release of ET- 1 by $16 \%$ but increased TGF- $\beta$ release by $10 \%$ from EECs.

When EECs were treated with LPS, the ET-1 levels in the culture supernatant was $6.1 \pm 0.03 \mathrm{ng} / \mathrm{ml}$ and TGF- $\beta$ levels were $5.66 \pm 0.08 \mathrm{ng} / \mathrm{ml}$ compared to the ET-1 levels of $6.63 \pm 0.01 \mathrm{ng} / \mathrm{ml}$ and TGF- $\beta$ levels of $6.56 \pm 0.05 \mathrm{ng} / \mathrm{ml}$ in the culture supernatant of untreated EECs $(n=6 ; p<$ $0.01)$. Thus, treatment of EECs with LPS reduced ET-1 secretion by $8 \%$ and TGF- $\beta$ secretion by $13.7 \%$ (Figures 4 and 5).

Angiotensin II levels were undetectable in all the culture supernatants.

\section{Discussion}

It is well recognized that vascular endothelial cells exert marked regulatory influence on subjacent non-endothelial cells such as myocytes, fibroblasts, pericytes and smooth muscle cells (SMCs) [9-13]. Given the regional differences in the functional properties of the endothe- 


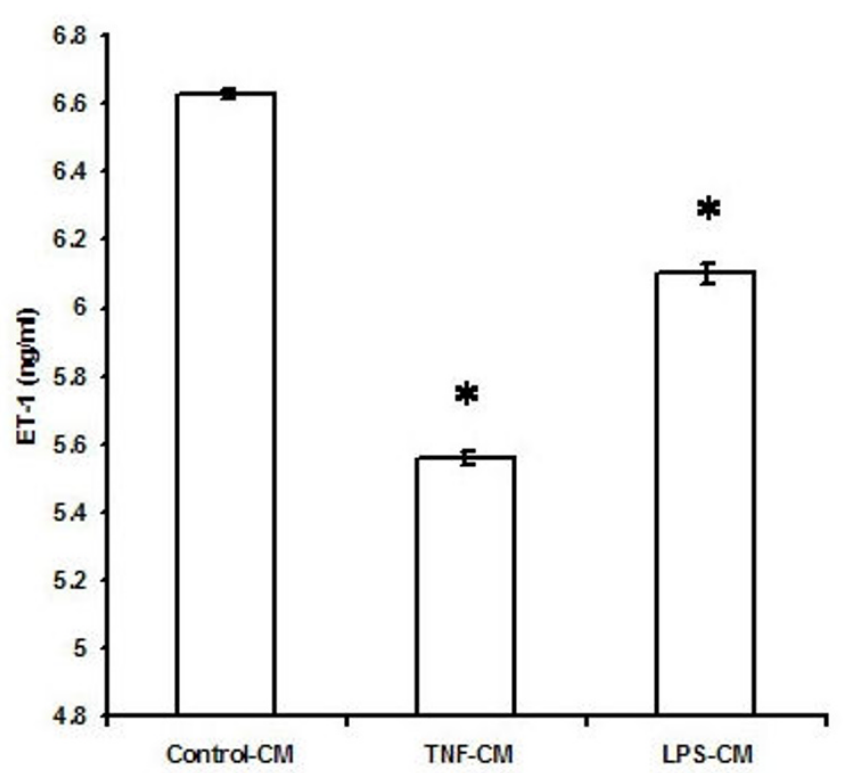

Figure 4

Effect of TNF- $\alpha$ and LPS on ET-I release by endocardial endothelial cells. The values are mean $\pm S D\left(n=6 ;{ }^{*} p\right.$ $<0.0 \mathrm{I}$ ). Control-CM = Conditioned medium from untreated endocardial endothelial cells, TNF-CM = Conditioned medium from endocardial endothelial cells treated with TNF$\alpha$, LPS-CM $=$ Conditioned medium from endocardial endothelial cells treated with LPS. ' $n$ ' is the number of times each experiment was done.

lium, we had earlier investigated the role of EE in modulating cardiac fibroblast proliferation and collagen synthesis and found that EE has a stimulatory effect on cardiac fibroblasts [5]. In the present study we explored whether pro - inflammatory agents such as TNF- $\alpha$ and LPS modulate this stimulatory effect. Interestingly, both TNF- $\alpha$ and LPS were found to attenuate the stimulatory effect of EE on cardiac fibroblasts.

The inflammatory effects of TNF- $\alpha$ and LPS on vascular endothelial cells are well - characterized. Endothelial cells obtained from different sites exhibit varied responses to cytokines and LPS [14]. However, the effects of TNF- $\alpha$ and LPS on endocardial endothelial cells have not been previously reported.

In the present study, $\left[{ }^{3} \mathrm{H}\right]$-Thymidine incorporation as well as rate of collagen synthesis were significantly lower in cardiac fibroblasts grown in conditioned medium from EECs treated with either TNF- $\alpha$ or LPS, when compared to the cells grown in EEC conditioned medium and not treated with either agents. Neither TNF- $\alpha$ nor LPS affected the viability of the cells. Concentrations of TNF- $\alpha$ up to $1000 \mathrm{ng} / \mathrm{ml}$ have been reported to cause reduction in col-

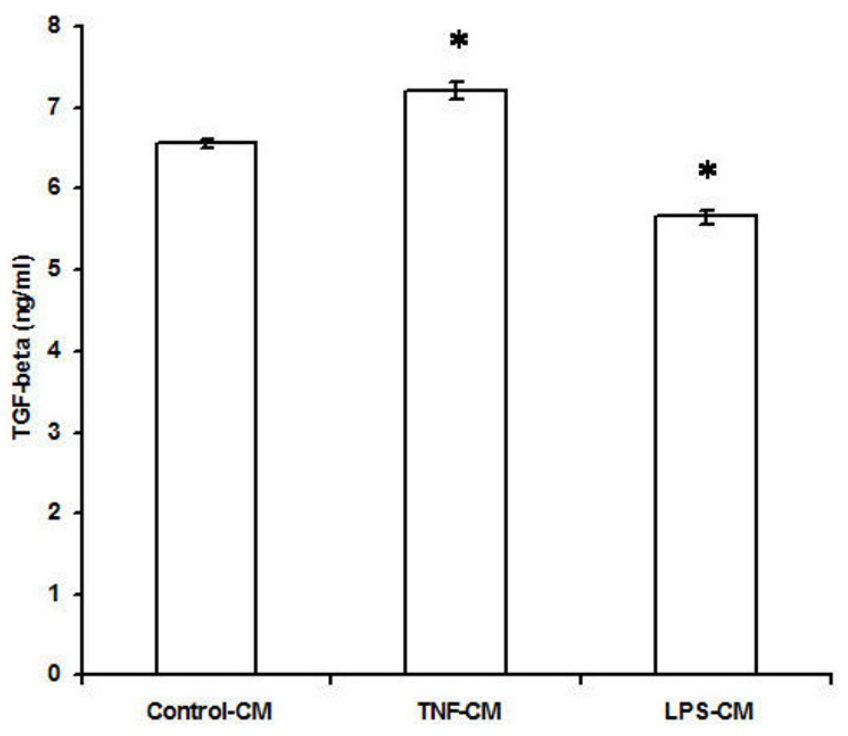

Figure 5

Effect of TNF- $\alpha$ and LPS on TGF- $\beta$ release by endocardial endothelial cells. The values are mean \pm SD $(n=$ 6 ; $^{*}<0.0 \mathrm{I}$ ). Control-CM = Conditioned medium from untreated endocardial endothelial cells, TNF-CM = Conditioned medium from endocardial endothelial cells treated with TNF- $\alpha$, LPS-CM = Conditioned medium from endocardial endothelial cells treated with LPS. ' $n$ ' is the number of times each experiment was done.

lagen synthesis in cardiac fibroblasts without affecting the cell numbers [15]. Our study demonstrated not only the direct inhibitory action of TNF- $\alpha$ on collagen synthesis in cardiac fibroblasts, but also its ability to attenuate the stimulatory effect of EECs on collagen production by cardiac fibroblasts. Yokoyama et al [16] proposed that TNF$\alpha$ could act as an autocrine/paracrine mediator in myocardial remodeling. The cytokine increases both the expression and activity of matrix metalloproteinases (MMPs) which regulate matrix turnover [17]. In studies investigating the direct effect of TNF- $\alpha$ on cardiac fibroblasts, it has been observed that the cytokine decreases total collagen synthesis $[18,19]$.

We also observed alterations in the release of endothelium-derived factors, such as NO, TGF- $\beta$ and ET- 1 into the conditioned medium when EECs were treated with TNF-a or LPS, which in turn could contribute to the altered response elicited in cardiac fibroblasts treated with the conditioned medium. EECs released significantly higher levels of nitrite in response to the pro-inflammatory agents. A notable action of TNF- $\alpha$ is its ability to induce nitric oxide synthase (NOS) activity in different cell types, including endocardial cells $[6,20]$. Nitric oxide $(\mathrm{NO})$ is an 
important modulator of TNF- $\alpha$ in the heart. In addition to being an immunomodulator and a potent inhibitor of platelet aggregation and cell migration, NO is also an antimitogen [21-23]. In a study using endothelial cells and SMCs from coronary arteries, inhibition of NO has been shown to cause an increase in the concentration of collagen types I and III. The data also supports an inhibitory role for NO on collagen synthesis [24]. Extrapolating these findings to the present study, it is tempting to postulate that the attenuation of the proliferative response in cardiac fibroblasts is the result of increased release of $\mathrm{NO}$ from EECs on treatment with TNF- $\alpha$ or LPS.

Levels of endothelin (ET-1) in the conditioned medium from EECs treated with TNF- $\propto$ or LPS were found to be lower, raising the possibility that a decrease in the levels of ET-1 may contribute to the diminished proliferative response in fibroblasts. Our earlier studies using endothelin inhibitors had shown that the stimulatory effect of EECs on cardiac fibroblasts is mediated by ET-1 [5].

Treatment of EECs with TNF- $\propto$ also resulted in an elevation of TGF- $\beta$ in the conditioned medium. Dose-dependent increase in TGF- $\beta$ release has been observed in microglial cells treated with TNF- $\propto$ [25]. It is possible that TNF- $\propto$ may regulate TGF- $\beta$ expression as a feed back mechanism to limit extra cellular degradation in response to injury. TGF- $\beta$ being inhibitory to cardiac fibroblast proliferation, the increased levels of this peptide in the conditioned medium from TNF- $\propto$ treated EECs obviously accentuates the attenuation of proliferation brought about by increased NO and decreased ET-1.

LPS causes cardiac dysfunction by enhancing cardiacderived inflammatory mediator expression, associated with the release of pro-inflammatory cytokines such as TNF- $\alpha$ and IL- $1 \beta$ and over production of NO $[26,27]$. Human coronary endothelial cells stimulated with LPS express higher levels of TNF mRNA and release increased levels of the cytokine [28]. Since most of the effects of LPS are through TNF, it can be assumed that in cardiac fibroblasts, the endotoxin elicits responses similar to that induced by TNF- $\alpha$.

In this study, we have explored the independent effects of TNF- $\alpha$ and LPS on fibroblast function mediated through major mediators released by EECs. It is possible that other EE-derived mediators are also involved in the modulation of fibroblast growth and collagen synthesis. A limitation of the study is the usage of cells from two different species, but in previous studies on the interaction of endothelial cells with their neighboring cells, others have also employed cells derived from different species [12].

\section{Conclusion}

This study suggests that pro-inflammatory cytokines can cause altered expression of paracrine factors in EECs, that in turn may inhibit proliferation and lower collagen synthesis in cardiac fibroblasts. The effects of TNF- $\alpha$ or LPS on EECs as observed in our study may be of significance in pathological conditions such as cardiac failure and during post inflammatory wound healing where different cytokines are up - regulated in the tissues.

\section{Competing interests}

The authors declare that they have no competing interests.

\section{Authors' contributions}

LK participated in the design of the study, carried out the tissue culture experiments, various assays, performed the statistical analysis and drafted the manuscript. CCK conceived of the study, participated in its design, participated in the writing of the manuscript and coordinated the study. Both authors read and approved the final manuscript.

\section{Acknowledgements}

The authors acknowledge the Department of Science and Technology, Government of India, for financial assistance and the Director of the Institute for facilities.

\section{References}

I. Shah AM: Paracrine modulation of heart cell function by endothelial cells. Cardiovasc Res 1996, 31 (6):847-867.

2. Brutsaert DL, Meulemans AL, Sipido KR, Sys SU: Effects of damaging the endocardial surface on the mechanical performance of isolated cardiac muscle. Circ Res 1988, 62(2):358-366.

3. Palmer JN, Hartogensis WE, Patten M, Fortuin FD, Long CS: Interleukin-I beta induces cardiac myocyte growth but inhibits cardiac fibroblast proliferation in culture. J Clin Invest 1995, 95(6):2555-2564.

4. Andries LJ, Sys SU, Brutsaert DL: Morphoregulatory interactions of endocardial endothelium and extracellular material in the heart. Herz 1995, 20(2): I35-145.

5. Kuruvilla L, Nair RR, Umashankar PR, Lal AV, Kartha CC: Endocardial endothelial cells stimulate proliferation and collagen synthesis of cardiac fibroblasts. Cell Biochem Biophys 2007, 47(I):65-72.

6. Smith JA, Radomski MW, Schulz R, Moncada S, Lewis MJ: Porcine ventricular endocardial cells in culture express the inducible form of nitric oxide synthase. $\mathrm{Br} J$ Pharmacol 1993, 108(4): I I07-III0.

7. Tan LB, Jalil JE, Pick R, Janicki JS, Weber KT: Cardiac myocyte necrosis induced by angiotensin II. Circ Res 1991, 9(5): I I85- I I95.

8. Diegelmann RF, Peterkofsky B: Collagen biosynthesis during connective tissue development in chick embryo. Dev Biol 1972, 28(3):443-453.

9. Baird A, Ling N: Fibroblast growth factors are present in the extracellular matrix produced by endothelial cells in vitro: implications for a role of heparinase-like enzymes in the neovascular response. Biochem Biophys Res Commun 1987, I 42(2):428-435.

10. Gajdusek C, DiCorleto P, Ross R, Schwartz SM: An endothelial cell-derived growth factor. J Cell Biol I 980, 85(2):467-472.

II. Gajdusek CM, Schwartz SM: Ability of endothelial cells to condition culture medium. J Cell Physiol 1982, I I 0(1):35-42.

12. Guarda E, Myers PR, Brilla CG, Tyagi SC, Weber KT: Endothelial cell induced modulation of cardiac fibroblast collagen metabolism. Cardiovasc Res 1993, 27(6): 1004-1008. 
13. Villanueva AG, Farber HW, Rounds S, Goldstein RH: Stimulation of fibroblast collagen and total protein formation by an endothelial cell-derived factor. Circ Res |99|, 69(I):|34-|4|.

14. Sano H, Tomita K, Hitsuda Y: Expression of vascular cell adhesion molecule-I on human pulmonary artery endothelial cells and human umbilical vein endothelial cells stimulated by tumor necrosis factor- $\alpha$, interleukin-I $\beta$ and lipopolysaccharide. Yonago Acta Medica 1997, 40:21-30.

15. Peng J, Gurantz D, Tran V, Cowling RT, Greenberg BH: Tumor necrosis factor-alpha-induced ATI receptor upregulation enhances angiotensin II-mediated cardiac fibroblast responses that favor fibrosis. Circ Res 2002, 9 I ( I 2): I I 19- I I 26.

16. Yokoyama T, Nakano M, Bednarczyk JL, Mclntyre BW, Entman M, Mann DL: Tumor necrosis factor-alpha provokes a hypertrophic growth response in adult cardiac myocytes. Circulation 1997, 95(5): 1247-1252.

17. Nian M, Lee P, Khaper N, Liu P: Inflammatory cytokines and postmyocardial infarction remodeling. Circ Res 2004, 94(I2): 1543-1553.

18. Sano I, Kusachi S, Murakami T, Ninomiya Y, Oka T, Nunoyama H, Kumashiro $\mathrm{H}$, Iwabu A, Ueta J, Tsuji T: OPC- a quinoline derivative, counteracts the reduction in type III collagen mRNA due to lipopolysaccharides in cultured rat cardiac fibroblasts. Jpn Heart J 82 I2, 42(I): 125-134.

19. Siwik DA, Chang DL, Colucci WS: Interleukin-Ibeta and tumor necrosis factor-alpha decrease collagen synthesis and increase matrix metalloproteinase activity in cardiac fibroblasts in vitro. Circ Res 2000, 86 ( I 2): | 259-। 265.

20. Balligand JL, Cannon PJ: Nitric oxide synthases and cardiac muscle. Autocrine and paracrine influences. Arterioscler Thromb Vasc Biol 1997, I 7( I 0): 1846-1858.

21. Lau YT, Ma WC: Nitric oxide inhibits migration of cultured endothelial cells. Biochem Biophys Res Commun 1996, 22 I(3):670-674.

22. Rizvi MA, Myers PR: Nitric oxide modulates basal and endothelin-induced coronary artery vascular smooth muscle cell proliferation and collagen levels. I Mol Cell Cardiol 1997, 29(7): 1779-1789.

23. Sarkar R, Webb RC, Stanley JC: Nitric oxide inhibition of endothelial cell mitogenesis and proliferation. Surgery 1995, I I 8(2):274-279.

24. Myers PR, Tanner MA: Vascular endothelial cell regulation of extracellular matrix collagen: role of nitric oxide. Arterioscler Thromb Vasc Biol 1998, 18(5):71 7-722.

25. Chao CC, Hu S, Sheng WS, Tsang M, Peterson PK: Tumor necrosis factor-alpha mediates the release of bioactive transforming growth factor-beta in murine microglial cell cultures. Clin Immunol Immunopathol I995, 77(3):358-365.

26. Chagnon F, Metz CN, Bucala R, Lesur O: Endotoxin-induced myocardial dysfunction: effects of macrophage migration inhibitory factor neutralization. Circ Res 2005, 96:1095-I I02.

27. Kruger S, Kunz D, Graf J, Stickel T, Merx MW, Koch KC, Janssens U, Hanrath P: Endotoxin hypersensitivity in chronic heart failure. Int J Cardiol 2007, I I5(2): I59-163.

28. Chan EL, Haudek SB, Giroir BP, Murphy JT: Human coronary endothelial cell activation by endotoxin is characterized by NF-kappa B activation and TNF-alpha synthesis. Shock 200I, 16(5):349-354.
Publish with Biomed Central and every scientist can read your work free of charge

"BioMed Central will be the most significant development for disseminating the results of biomedical research in our lifetime. "

Sir Paul Nurse, Cancer Research UK

Your research papers will be:

- available free of charge to the entire biomedical community

- peer reviewed and published immediately upon acceptance

- cited in PubMed and archived on PubMed Central

- yours - you keep the copyright

Submit your manuscript here:

http://www.biomedcentral.com/info/publishing_adv.asp
BioMedcentral 